\title{
ANALISIS KEMAMPUAN BERPIKIR KREATIF SISWA SMP MELALUI SOAL OPEN ENDED PADA MATERI BANGUN TABUNG
}

\author{
Rosita Dwi Ferdiani $^{1}$, Nur Farida ${ }^{2}$, Tatik Retno Murniasih ${ }^{3}$ \\ 1,2,3 Universitas Kanjuruhan Malang \\ rositadf@unikama.ac.id ${ }^{1}$, nurfarida@unikama.ac.id ${ }^{2}$, tretnom@unikama.ac.id ${ }^{3}$
}

\begin{abstract}
ABSTRAK
Tujuan penelitian ini untuk menganalisis kemampuan berpikir kreatif pada materi tabung. Peningkatan kreativitas dapat dilakukan melalui pembelajaran matematika di sekolah. Berdasarkan wawancara dengan guru matematika di MTs Miftahul Ulum Ngembal, didapat informasi bahwa kurangnya kemampuan siswa khususnya kelas IX dalam menyelesaikan permasalahanpermasalahan matematika yang membutuhkan pemikiran kreativitas. Kurang kemampuan ini disebabkan kurangnya kebiasaan yang membutuhkan pemikiran kreatif. Siswa dibiasakan untuk mengerjakan permasalahan rutin atau soal-soal pengaplikasian rumus yang terdapat di buku pelajaran atau di LKS. Subjek penelitian ini adalah 3 siswa dari 38 siswa. Indikator yang digunakan dalam penelitian ini adalah indikator kemampuan berpikir kreativitas yaitu kelancaran, fleksibel, dan orisinil. Dari hasil penelitian didapatkan subjek 1 mempunyai kemampuan dalam berpikir lancar, fleksibel dan orisinal. Subjek 2 mempunyai kemampuan berpikir lancar dan orisinal. Subjek 3 mempunyai kemampuan berpikir orisinal.
\end{abstract}

Kata kunci: berpikir kreatif, open ended, tabung.

\begin{abstract}
Purpose of this study was to analyze the ability to think creatively on tube material. Increased The creativity can be done through learning mathematics at school. Based on interviews with mathematics teachers at MTs Miftahul Ulum Ngembal, information was obtained that the lack of ability of students, especially class IX, to solve mathematical problems that required creativity thinking. This lack of ability is due to a lack of habits that require creative thinking. Students are accustomed to working on routine problems or questions about the application of formulas found in textbooks or on Student exercise book. The subjects of this study were 3 students from 38 students. The indicators used in this study are indicators of the ability to think of creativity, namely fluency, flexibility, and originality. From the results of the study found subject 1 has the ability to think fluently, flexibly and original. Subject 2 has the ability to think fluently and original. Subject 3 has original thinking skills.
\end{abstract}




\section{Rosita Dwi Ferdiani, Nur Farida, Tatik Retno Murniasih}

Keywords: creative thinking, open ended, tube

\section{PENDAHULUAN}

Perkembangan teknologi saat ini, mendorong manusia untuk memanfatkan teknologi di segala aspek kehidupan. Pemanfaatan teknologi ini membutuhkan kreatifitas dalam pengunaannya. Kreativitas diperlukan dalam menghadapi tantangan di masa depan. (Sriraman, 2005). Peningkatan kreativitas ini dapat dilakukan di segala jenjang pendidikan formal, dari sekolah dasar sampai perguruan tinggi. Hal ini sejalan dengan salah satu tujuan pendidikan nasional yaitu mengembangkan potensi siswa agar menjadi manusia yang kreatif.

Pembelajaran di kelas hendaknya dilakukan melalui aktivitas-aktivitas yang mendorong kreativitas siswa. Peningkatan kreativitas membutuhkan waktu dan pengalaman-pengalaman yang membutuhkan pemikiran kreatif (Mann, 2006). Guru dapat mendorong bakat kreatif siswa dengan cara melatih siswa untuk menciptakan solusi baru dan bermanfaat dan mensimulasikan ke dalam dunia nyata (Chamberlin \& Moon, 2005). Menurut Liljedahl \& Sriraman (2006) kemampuan siswa untuk menyajikan ide-ide baru dan/atau menemukan solusi dalam masalah matematika dianggap sebagai indikator kreativitas.

Pada pembelajaran matematika, siswa dilatih untuk menyelesaikan permasalahan-permasalahan matematika yang berkaitan dengan kehidupan seharihari. Matematika memberikan peluang bagi siswa untuk mengerjakan tugas-tugas yang menantang, bermanfaat dan membutuhkan pemikiran kreatif (Vale \& Barbosa, 2015). Salah satu tugas yang dapat menumbuhkan kreativitas adalah tugas open ended (Nohda, 2000).

Berdasarkan wawancara dengan guru matematika di MTs Miftahul Ulum Ngembal, didapat informasi bahwa kurangnya kemampuan siswa khususnya kelas IX dalam menyelesaikan permasalahan-permasalahan matematika yang membutuhkan pemikiran kreatif. Kurang kemampuan ini disebabkan kurangnya kebiasaan yang membutuhkan pemikiran kreatif. Siswa dibiasakan untuk mengerjakan permasalahan rutin atau soal-soal pengaplikasian rumus yang terdapat di buku pelajaran atau di LKS. Sehingga apabila diberikan permasalahan yang membutuhkan pemikiran kreatif, siswa merasa kesulitan. Hal ini terlihat 
jelas pada materi tabung. Pada saat siswa diminta membuat jaring- jaring tabung, siswa merasa kesulitan, dan hanya meniru model jaring-jaring tabung yang disajikan di buku. Siswa kesulitan dalam menentukan ukuran selimut tabung, akhirnya tidak terbentuk tabung yang sempurna.

Kreativitas dimulai dengan rasa ingin tahu yang melibatkan siswa dalam mengeksplorasi dan bereksperimen, meningkatkan imajinasi dan orisinalitas mereka (Vale and Barbosa, 2015). Kreativitas melibatkan pemikiran yang berbeda, penalaran yang lebih tinggi, yang menyoroti tiga indikator utama yaitu kelancaran, fleksibilitas, dan orisinalitas (kebaruan). Kelancaran adalah kemampuan untuk menghasilkan sejumlah besar solusi berbeda yang diperoleh siswa untuk tugas yang sama. Fleksibilitasnya adalah kemampuan untuk menghasilkan berbagai ide yang berbeda pada masalah yang sama, yang diatur dalam berbagai kategori. Orisinalitas adalah kemampuan untuk menciptakan ideide yang unik dibandingkan dengan siswa dalam kelompok yang sama (Vale dkk, 2012). Berikut ini adalah indikator kreativitas.

Tabel 1. Indikator Kreativitas

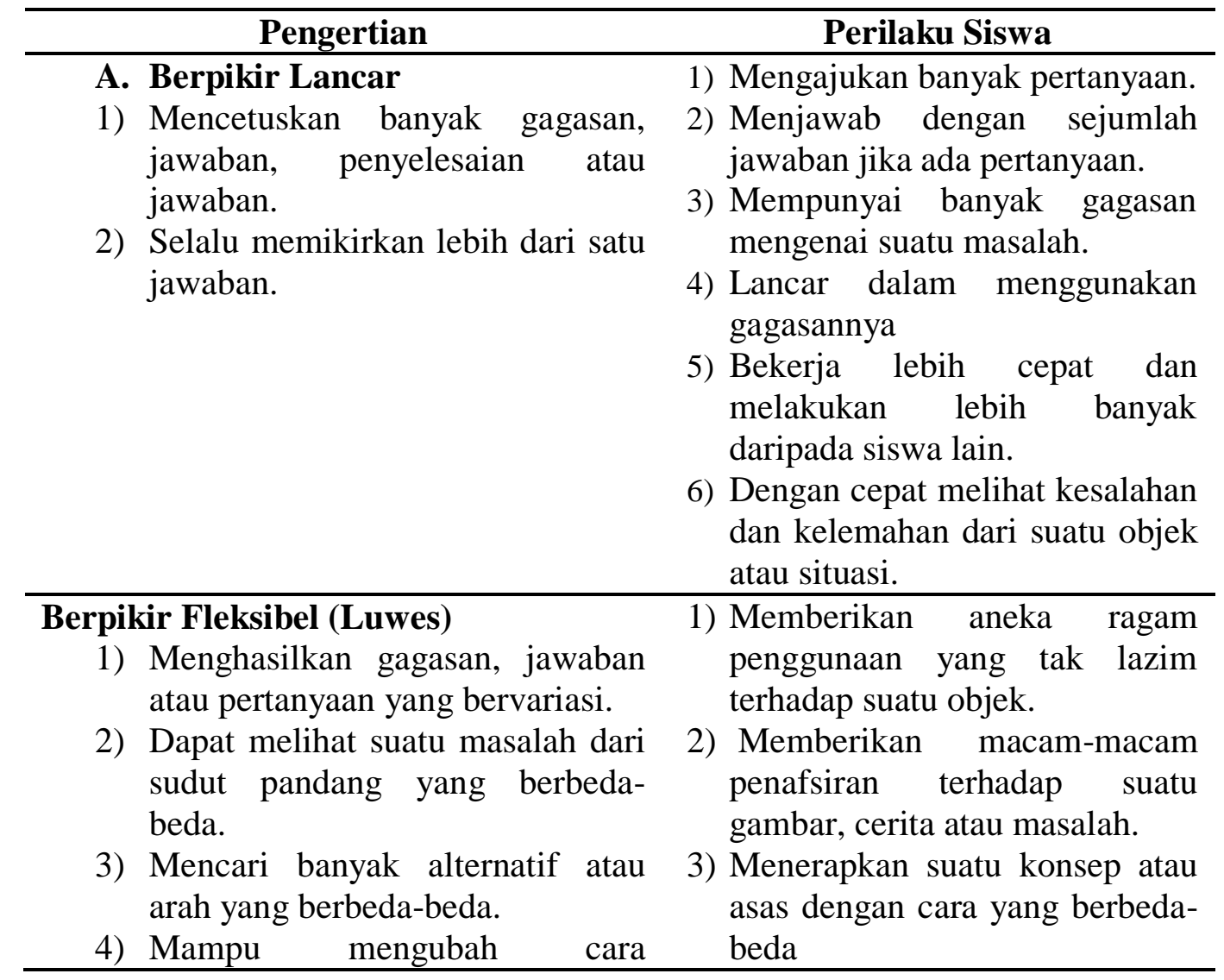




\begin{tabular}{|c|c|}
\hline \multirow[t]{4}{*}{ pendekatan atau pemikiran. } & $\begin{array}{l}\text { 4) Memberikan pertimbangan atau } \\
\text { mendiskusikan sesuatu }\end{array}$ \\
\hline & $\begin{array}{l}\text { 5) Selalu memiliki posisi yang } \\
\text { berbeda atau bertentangan } \\
\text { dengan mayoritas kelompok. }\end{array}$ \\
\hline & $\begin{array}{l}\text { 6) Jika diberi suatu masalah } \\
\text { biasanya memikirkan macam- } \\
\text { macam cara yang berbeda-beda } \\
\text { untuk menyelesaikannya. }\end{array}$ \\
\hline & $\begin{array}{l}\text { 7) Menggolongkan hal-hal yang } \\
\text { menurut pembagian atau } \\
\text { kategori yang berbedabeda. } \\
\text { 8) Mampu mengubah arah berpikir } \\
\text { secara spontan. }\end{array}$ \\
\hline \multirow{8}{*}{$\begin{array}{l}\text { Berpikir Orisinal } \\
\text { 1) Mampu melahirkan ungkapan yang } \\
\text { baru dan unik. } \\
\text { 2) Memikirkan cara-cara yang tak lazim } \\
\text { untuk mengungkapkan diri. } \\
\text { 3) Mampu membuat kombinasi- } \\
\text { kombinasi yang tak lazim dari bagian- } \\
\text { bagian atau unsur-unsur. }\end{array}$} & masalah-masalah \\
\hline & $\begin{array}{l}\text { atau hal yang tak pernah } \\
\text { terpikirkan orang lain. }\end{array}$ \\
\hline & $\begin{array}{l}\text { 2) Mempertanyakan cara-cara } \\
\text { lama dan berusaha memikirkan }\end{array}$ \\
\hline & cara-cara baru. \\
\hline & $\begin{array}{l}\text { 3) Memilih a-simetri dalam } \\
\text { membuat gambar atau desain. }\end{array}$ \\
\hline & $\begin{array}{l}\text { 4) Mencari pendekatan baru dari } \\
\text { stereotype. }\end{array}$ \\
\hline & $\begin{array}{lcr}\text { 5) Setelah mendengar atau } \\
\text { membaca gagasan, bekerja } \\
\text { untuk }\end{array}$ \\
\hline & \\
\hline
\end{tabular}

(Sumber: Mursidik dkk, 2014)

\section{METODE PENELITIAN}

Data yang digunakan dalam penelitian ini adalah data siswa kelas IX dengan populasi 38 siswa. Data yang digunakan dalam penelitian ini dibedakan menjadi dua macam yakni: 1) Data Primer, yaitu sumber yang langsung memberi data kepada peneliti. Adapun yang menjadi sumber data primer dalam penelitian ini adalah informasi dari guru mata pelajaran matematika, dan hasil pekerjaan siswa. 2) Data Sekunder, yaitu data yang langsung dikumpulkan oleh peneliti dari sumber yang sudah ada, seperti dokumentasi, jurnal, dan sumber buku. Subjek dalam penelitian ini berjumlah 3 siswa. Pengambilan subjek penelitian dilakukan secara acak. Pemilihan subjek penelitian berdasarkan kemampuannya, yaitu 
berkemampuan rendah, sedang, dan tinggi. Adapun hal yang digunakan peneliti dalam instrumen penelitian ini antara lain:

a) Lembar pengamatan dalam penelitian ini berisi hasil pengamatan yang dilakukan peneliti terhadap siswa Lembar pengamatan berisi tentang lembar validasi soal dan kisi-kisi indikator jawaban siswa.

b) Lembar tes digunakan sebagai alat untuk mengumpul data mengenai kemampuan berpikir kreatif siswa pada materi tabung. Tes yang digunakan dalam penelitian ini berbentuk essay, dimana siswa diminta merancang jaringjaring tabung. Materi yang yang dipakai dalam tes adalah menyelesaikan permasalahan yang terkait unsur-unsur dan sifat tabung.

c) Peneliti menggunakan pengumpulan data sekunder dengan pedoman wawancara untuk mendapatkan data berupa informasi tentang kemampuan berpikir kreatif dalam mengerjakan soal tes yang diberikan. Pedoman wawancara berisi pertanyaan-pertanyaan yang ditanyakan peneliti untuk memperkuat hasil pengumpulan data. Pertanyaan yang disusun dan diajukankepada siswa setelah selesai melakukan tes soal.

\section{HASIL PENELITIAN DAN PEMBAHASAN}

Setelah melakukan validasi ke validator, instrumen penelitian berupa soal tes diberikan ke siswa untuk dikerjakan. Soal yang diberikan adalah siswa diminta untuk merancang jarring-jaring tabung dengan ukuran yang ditentukan oleh siswa. Berdasarkan hasil pekerjaan siswa, didapatkan hasil sebagai berikut:

Tabel 2. Hasil Pekerjaan Subjek Penelitian

\begin{tabular}{cll}
\hline Subjek & Hasil pekerjan & \multicolumn{2}{c}{ Analisis } \\
\hline 1 & 1) & Subjek 1 dapat berpikir lancar, \\
karena mempunyai banyak & gagasan mengenai jaring- \\
& jaring tabung, lancar dalam \\
& menggunakan gagasannya, \\
& bekerja lebih cepat daripada \\
& siswa lain, dengan cepat \\
& melihat kesalahan dan \\
& kelemahan dari suatu objek \\
& atau situasi. Subjek 1 \\
& membuat jaring-jaring tabung \\
& dengan desain yang berbeda. \\
\hline
\end{tabular}




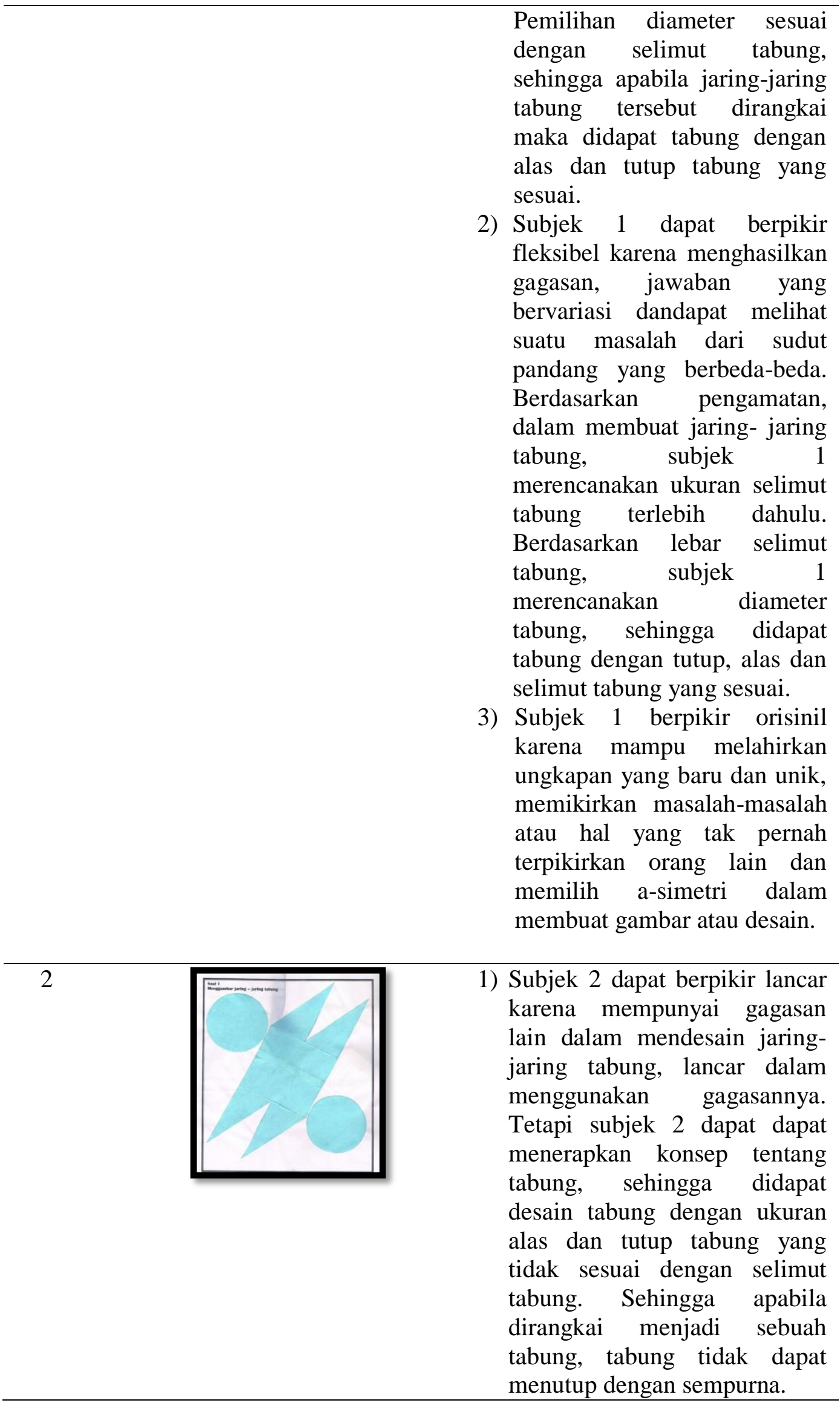




\begin{tabular}{|c|c|}
\hline & $\begin{array}{l}\text { 2) Subjek } 2 \text { berpikir orisinal } \\
\text { karena mampu melahirkan } \\
\text { ungkapan yang baru dan unik, } \\
\text { dan berbeda dengan subjek } \\
\text { lainnya. }\end{array}$ \\
\hline 3 & $\begin{array}{l}\text { 1) Subjek } 3 \text { dapat berpikir orisinal } \\
\text { karena mampu melahirkan } \\
\text { ungkapan yang baru dan unik, } \\
\text { dan berbeda dengan subjek } \\
\text { lainnya.Tetapi subjek 3, tidak } \\
\text { memahami konsep tabung, } \\
\text { sehingga dalam merancang } \\
\text { tutup dan alas tabung tidak } \\
\text { sesuai dengan selimut tabung. } \\
\text { Apabila dirangkai menjadi } \\
\text { sebuah tabung, maka tidak } \\
\text { dapat menjadi tabung yang } \\
\text { tertutup rapat. }\end{array}$ \\
\hline
\end{tabular}

Penelitian ini bertujuan untuk menganalisis kemampuan berpikir kreatif siswa pada materi bangun tabung. Analisis kemampuan berpikir kreatif ini menggunakan indikator berpikir kreatif yaitu kelancaran, fleksibilitas dan orisinalitas (kebaruan). Untuk mengembangkan kemampuan berpikir kreatif siswa diperlukan soal-soal yang menantang siswa, misalkan soal open ended (Briggs \& Davis dalam Damayanti \& Sumardi, 2018). Salah satu soal open ended yang digunakan dalam penelitian ini adalah membuat atau mendesain jaring - jaring tabung. Dari hasil tes ketiga subjek penelitian didapatkan bahwa subjek membuat atau mendesain jaring-jaring tabung dengan beragam jawaban. Sehingga akan terlihat kemampuan berpikir kreatif siswa. Soal yang membutuhkan lebih dari satu jawaban (open ended) dapat digunakan untuk mengetahui kemampuan berpikir kreatif siswa ( Elly's dalam Nasution dkk, 2017). Hal ini sejalan Becker \& Shimada (dalam Damayanti \& Sumardi, 2018) yang menyatakan bahwa masalah dalam soal open ended dapat dirumuskan untuk mendapatkan jawaban yang benar. Aspek dalam open ended dapat diklasifikasikan menjadi tiga jenis; 1) proses penyelesaian masalah, yaitu masalah yang memiliki beberapa cara untuk dipecahkan, 2) hasilnya, bahwa ia memiliki banyak jawaban yang benar, dan 3) 


\section{Rosita Dwi Ferdiani, Nur Farida, Tatik Retno Murniasih}

pengembangan lebih lanjut, yaitu ketika siswa telah selesai sesuatu, maka mereka dapat mengembangkan masalah baru yang terkait dengan masalah sebelumnya

Berdasarkan hasil analisis kemampuan berpikir kreatif didapatkan bahwa subjek 1 mempunyai kemampuan dalam berpikir lancar, fleksibel dan orisinal. Sedangkan subjek 2 mempunyai kemampuan berpikir lancar dan orisinal. Subjek 3 mempunyai kemampuan berpikir orisinal.

\section{SIMPULAN}

Berdasarkan hasil analisis kemampuan berpikir kreatif siswa SMP melalui soal open ended pada materi bangun tabung didapatkan hasil:

1. Subjek 1 mempunyai kemampuan dalam berpikir lancar, fleksibel dan orisinal. Hal ini dikarenakan:

a. Subjek 1 dapat berpikir lancar, yaitu mempunyai banyak gagasan mengenai jaring-jaring tabung, lancar dalam menggunakan gagasannya, bekerja lebih cepat daripada siswa lain, dengan cepat melihat kesalahan dan kelemahan dari suatu objek atau situasi. Subjek 1 membuat jaringjaring tabung dengan desain yang berbeda. Pemilihan diameter sesuai dengan selimut tabung, sehingga apabila jaring-jaring tabung tersebut dirangkai maka didapat tabung dengan alas dan tutup tabung yang sesuai.

b. Subjek 1 dapat berpikir fleksibel karena menghasilkan gagasan, jawaban yang bervariasi dandapat melihat suatu masalah dari sudut pandang yang berbeda-beda. Berdasarkan pengamatan, dalam membuat jaring- jaring tabung, subjek 1 merencanakan ukuran selimut tabung terlebih dahulu. Berdasarkan lebar selimut tabung, subjek 1 merencanakan diameter tabung, sehingga didapat tabung dengan tutup, alas dan selimut tabung yang sesuai.

c. Subjek 1 berpikir orisinil karena mampu melahirkan ungkapan yang baru dan unik, memikirkan masalah-masalah atau hal yang tak pernah terpikirkan orang lain dan memilih a-simetri dalam membuat gambar atau desain.

2. Subjek 2 mempunyai kemampuan berpikir lancar dan orisinal. Hal ini dikarenakan: 
a. Subjek 2 dapat berpikir lancar karena mempunyai gagasan lain dalam mendesain jaring-jaring tabung, lancar dalam menggunakan gagasannya. Tetapi subjek 2 dapat dapat menerapkan konsep tentang tabung, sehingga didapat desain tabung dengan ukuran alas dan tutup tabung yang tidak sesuai dengan selimut tabung. Sehingga apabila dirangkai menjadi sebuah tabung, tabung tidak dapat menutup dengan sempurna.

b. Subjek 2 berpikir orisinal karena mampu melahirkan ungkapan yang baru dan unik, dan berbeda dengan subjek lainnya.

3. Subjek 3 mempunyai kemampuan berpikir orisinal. Hal ini dikarenakan subjek 3 dapat mampu melahirkan ungkapan yang baru dan unik, dan berbeda dengan subjek lainnya. Akan tetapi, subjek 3 tidak memahami konsep tabung, sehingga dalam merancang tutup dan alas tabung tidak sesuai dengan selimut tabung. Apabila dirangkai menjadi sebuah tabung, maka tidak dapat menjadi tabung yang tertutup rapat.

\section{DAFTAR PUSTAKA}

Chamberlin, S., \& Moon, S. (2005). Model-eliciting activities as a tool to develop and identify creatively gifted mathematicians. Journal of Secondary Gifted Education, 17(1), 37-47.

Damayanti, H. T, Sumardi. (2018). Mathematical Creative Thinking Ability of Junior High School Students in Solving Open-Ended Problem. Journal of Research and Advances in Mathematics Education, 3(1), 36-45.

Liljedahl, P. \& Sriraman, B. (2006). Musings on Mathematical Creativity. For The Learning of Mathematics, 26(1), 20-23.

Mann, E. (2006). Creativity: The Essence of Mathematics. Journal for the Education of the Gifted, 30(2), 236-260.

Mursidik, M. E., Samsiyah, N., \& Rudyanto, E. H. (2014). Analisis Kemampuan Berpikir Kreatif Siswa SD dalam Memecahkan Masalah Matematika Open-Ended Ditinjau dari Tingkat Kemampuan Matematika. Jurnal $L P P M, 2(1), 7-13$.

Nasution, T. K, Surya E., Asmin, \& Sinaga, B. (2017). An Analysis of Student's Mathematical Creative Thinking Ability Senior High School on Geometry. International Journal of Advance Research and Innovative Ideas in Education, 3(2). 3860-3866.

Nohda, N. (2000). Teaching by Open-Approach Method in Japanese Mathematics Classroom. In T. Nakahara \& M. Koyama (Eds.), Proceedings of the Conference of the International Group for the Psychology of Mathematics Education (PME), 24(1), 39-55. Retrieved from http://files.eric.ed.gov/fulltext/ED466736.pdf 
Sriraman, B. (2005). Are Giftedness and Creativity Synonyms in Mathematics?. Journal of Secondary Gifted Education, 17(1), 20-36.

Vale, Isabel, and Barbosa, A. (2015). Mathematics Creativity in Elementary Teacher Training. Journal of the European Teacher Education, 10. 101109

Vale, I., Pimentel, T., Cabrita, I., Barbosa, A. \& Fonseca, L. 2012. Pattern problem solving tasks as a mean to foster creativity in mathematics. Tso, T. Y. (Ed), Opportunities to learn in mathematics education. Proceedings of the 36th Conference of the International Group for the Psychology of Mathematics Education, vol. 4, pp. 171-178. Taipei, Taiwan: PME 